\title{
ESTUDO DA RELIGIOSIDADE DO SUL DO TERRITÓRIO ACTUALMENTE PORTUGUÊS EM ÉPOCA ROMANA (SÉCS. I A. C.-III D. C.). ASPECTOS DE UMA METODOLOGIA.
}

Sílvia Teixeira ${ }^{1}$

\section{RESUMO}

Este artigo expõe, sucintamente, as opções metodológicas seguidas pela signatária como parte integrante da sua abordagem à religiosidade do Sul do território atualmente português em época romana, observando as suas eventuais potencialidades e problemas. O exame e descrição destas opções permitir-nos-ão perceber como poderemos, a partir dos dados epigráficos votivos, delinear um quadro caracterizador das divindades veneradas e respectivos cultuantes; bem como assimilar as informações obtidas face a outros âmbitos regionais na mesma linha cronológica, e aferir as suas eventuais variações em esferas mais restritas dentro do contexto em questão, numa perspectiva comparativa. A integração do fenômeno religioso no processo evolutivo das sociedades, particularmente na sua romanização, confere a esta questão uma certa importância para a construção e/ou consolidação do perfil identitário das regiões alentejana e algarvia desde a época romana, atentando em simultâneo nas suas especificidades territoriais e integração no âmbito global da Lusitânia romana, coincidente em boa parte com o atual território nacional.

Palavras-chave: metodologia; divindades; cultuantes; epigrafia; perspectiva comparativa.

\section{ABSTRACT}

This article succinctly presents the methodological options employed by the writer as a part of her approach to the religion of the Southern Portuguese territory in Roman times, noting their potential as well as some issues they may bring up. The review and description of these options enable us to perceive how it is possible to outline, using the data from votive inscriptions, a portrayal of the deities and their respective worshippers; as well as to assimilate the information obtained in comparison with other regional spheres in the same timeline, and also to assess the variations it may present on narrower scales contained within the aforementioned context, from a comparative standpoint. The assimilation of the religious phenomenon as a part of societal evolution, particularly their Romanization, provides this question with some importance in the construction and/or consolidation of the identity of the Alentejo and Algarve regions since Roman times, paying simultaneous attention to their specific traits territory-wise and their integration in the global context of Roman Lusitania, a good part of which overlaps with the current Portuguese territory.

Keywords: methodology; deities; worshippers; epigraphy; comparative approach.

\section{RESUMEN}

\footnotetext{
${ }^{1}$ Estudante de Doutoramento - Faculdade de Letras da Universidade de Lisboa. Rua Engenheiro Quartim Graça, 21, 2oㅡㄴ $\quad \mathrm{Dt}^{\circ}, \quad$ 1750-099 Lisboa (Portugal); (+351) 918500890; silvia_teixeira16@yahoo.com.
} 
Este artículo presenta sucintamente las opciones metodológicas seguidas por la autora como parte de su abordaje a la religiosidad del Sur del actual territorio portugués en época romana, observando su potencial y algunos posibles problemas. El examen y descripción de estas opciones nos permiten darnos cuenta de como podremos esbozar, a partir de los datos epigráficos votivos, una imagen de las deidades veneradas y sus respectivos cultuantes; así como asimilar las informaciones obtenidas en comparación con otros ámbitos regionales en la misma línea cronológica, y apreciar sus eventuales variaciones en ámbitos más restrictos en el contexto en cuestión, desde una perspectiva comparativa. La integración del fenómeno religioso en el proceso evolutivo de las sociedades, particularmente en su romanización, atribuye a esta cuestión importancia en la construcción y/o afirmación de la identidad de las regiones de Alentejo y Algarve desde la época romana, prestando simultánea atención a sus particularidades territoriales e integración en el ámbito global de Lusitania romana, coincidente, en una considerable parte, con el actual territorio portugués.

Palabras clave: metodología; deidades; cultuantes; epigrafía; perspectiva comparativa.

\section{Preâmbulo. Breve enquadramento temático}

Este trabalho procura desenvolver alguns aspectos concernentes à metodologia seguida na elaboração da dissertação de Mestrado da signatária, Cultos e cultuantes do Sul do território português em época romana (sécs. I a. C.-Ill d. C.). Uma aproximação à sociologia das religiões, apresentada à Faculdade de Letras de Lisboa em Abril de 2015. O termo "metodologia" surge a partir da palavra grega para "método" (methodos), que detém o significado de "caminho conducente a um fim", designando o conjunto de regras observadas a fim de alcançar um propósito, que, no caso da investigação científica, consiste no conhecimento; diferindo daquele conceito na medida em que se foca na descrição do método, visando a melhor compreensão do mesmo (CARMO, 1994: 288).

Como podemos ver pelo título da dissertação, o desenvolvimento da mesma assenta sobre a ideia de que o fenômeno religioso se reveste de um nítido caráter social, constituindo um quadro de referência para a identificação e explicação dos fenômenos humanos (CARMO, 1994: 59), e exercendo considerável influência sobre os propósitos e condutas dos indivíduos; como já haviam defendido E. Durkheim (1996), K. Marx (1844) e M. Weber (1995) nos primórdios da sociologia das religiões enquanto domínio cognitivo, a qual tem como objeto central de estudo o fenômeno religioso na sua vertente simultaneamente transformável e transformante face à sociedade.

O pendor social deste justifica que a sua metodologia de estudo deva integrar as abordagens inerentes às ciências sociais, seguindo as mesmas etapas no processo de investigação, entre as quais a definição do problema ou questão para que se pretende resposta e dos objetivos; a recolha dos dados; o seu tratamento e interpretação da informação resultante; e a apresentação dos dados, que culminou com a redação da dissertação supracitada. A descrição das opções

\begin{tabular}{|l|l|l|l|l|l|l|}
\hline (C) Rev. Arqueologia Pública & Campinas, SP & v. 9 & n. 2 & $57-71$ & DEZ 2015 & ISSN 2237-8294 \\
\hline
\end{tabular}




\section{Revista de Arqueologia Pública}

metodológicas inerentes ao desenvolvimento da mesma será, então, doravante apresentada no âmbito desta sucessão de etapas.

Dentro das referidas abordagens poderemos situar o método comparativo, o qual tem vindo a deter um lugar de relevo no pensamento ocidental desde a época de Heródoto, sendo atualmente utilizado em diversas ciências sociais, entre as quais a religião, não obstante as críticas posteriormente colocadas ao mesmo. Efetivamente, a comparação constitui algo inescapável ao pensamento lógico, uma vez que apenas podemos assimilar conceitualmente o que nos é desconhecido face ao que nos é familiar (ROSCOE, 2009: 25-26). Porém, entre os problemas levantados por este método, comuns a diversas áreas de estudo, parece emergir como discussão central a definição do que é ou não comparável, assente na oposição entre uma abordagem mais "científica", pautada pelo rigor e formalidade das comparações; e outra mais "humanística", defendendo a singularidade das culturas, que justificaria então a inviabilidade do processo comparativo, bem como a ideia de que este método distorce os dados a comparar, dada a possibilidade da sua obtenção através de diferentes fontes e meios (ROSCOE, 2009: 30-31).

\section{DELINEAÇÃo DE UMA QUESTÃo CENTRAL E OBJETIVOS. ALGUNS PROBLEMAS DE TERMINOLOGIA E METODOLOGIA}

O principal objetivo deste trabalho passa pela análise da representação dos diferentes tipos de cultos e respectivas divindades de âmbito particular no Sul do território atualmente português (englobando as regiões do atual Alentejo e Algarve) e caracterização dos mesmos a partir de aspectos de análise como os santuários, ritos, etc., bem como dos seus cultuantes do ponto de vista sociojurídico; numa tentativa de caracterização da religiosidade, enquanto fenômeno social, deste âmbito geográfico durante a ocupação romana, mais precisamente entre os sécs. I a. C. - III d. C, a qual constitui a questão central do trabalho.

Tendo ainda em conta o carácter social do fenômeno religioso acima referido, o desenvolvimento desta questão permitir-nos-á uma aproximação ao processo de romanização do Sul do território atualmente português, no concernente ao seu ritmo e eventuais particularidades; nomeadamente no sentido de se averiguar a dicotomia existente entre este e as terras interiores entre o Tejo e o Douro, bem como a Norte deste último, tendo a literatura respeitante a esta temática (ALARCÃO, 2002 $:$ 165) vindo a caracterizar o Sul do território atualmente português como o mais precoce e solidamente romanizado dos dois âmbitos regionais.

A questão central deste trabalho afigura-se passível de enquadramento num contexto temático global, que se foca na análise e caracterização da religiosidade lusitana, definida por $\mathrm{J}$. de Hoz (1986: 32) como o conjunto de dados oriundos da Lusitânia referentes ao complexo de crenças

\begin{tabular}{|l|l|l|l|l|l|l|}
\hline (C) Rev. Arqueologia Pública & Campinas, SP & v. 9 & n. 2 & $57-71$ & DEZ 2015 & ISSN 2237-8294 \\
\hline
\end{tabular}




\section{Revista de Arqueologia Pública}

religiosas que, embora com alguns traços particulares, seria partilhado por diversos povos préromanos de origem indoeuropeia, dentro e fora do território da Península lbérica.

Esta temática pode ser enquadrada em duas vertentes: o panteão e o ritual, sendo que 0 primeiro apresenta, como aspectos de estudo, a sua distribuição, tipologia das invocações e formulário, suporte material das inscrições, e extensão e distribuição do culto (HOZ, 1986: 33; 35-36). No que diz respeito ao primeiro, a Lusitânia destaca-se como a única região da antiga Hispânia cuja epigrafia latina regista a presença de teônimos indígenas (juntamente com uma parte da Tarraconense), revelando-se a documentação epigráfica do Ocidente peninsular prolixa em teônimos desconhecidos no território da Celtibéria e Hispânia oriental em geral (PRÓSPER, 2002: 16). Por esta razão, o estudo do repertório epigráfico votivo apresenta-se como um importante meio de conhecimento da religiosidade das comunidades lusitano-romanas, particularmente da sua componente autóctone.

Já no tocante à tipologia das invocações, J. de Hoz (1986: 35) enumera quatro casos: teônimo e epíteto, apenas um ou outro, e apelativos latinos comuns como deo seguidos de um teônimo ou epíteto indígena (ou ambos); detendo os epítetos um importante potencial informativo na caracterização das divindades (HOZ, op. cit.: 40). A nível do formulário, o destaque vai para as expressões votum solvit libens merito ("cumpriu merecidamente o voto") ou animo libens votum solvit ("cumpriu de bom grado o voto"), aram posuit ("colocou a ara"), ex voto ("por voto") e sacrum ("consagrado a...") (HOZ, 1986: 35, traduções da autora), entre outras; sendo ainda comum a utilização de formulário nitidamente latino em relação com divindades indígenas (ENCARNAÇÃO e GUERRA, 2010: 97). Por fim, a extensão e distribuição do culto prende-se com o local e frequência de surgimento dos teônimos dentro do território da Lusitânia, apresentando-se mais frequente o registo das divindades por uma única vez (HOZ, 1986: 36), embora os testemunhos únicos nem sempre assegurem a atribuição de um caráter tópico às divindades (ALARCÃO, 2002 ${ }^{4}: 158$ ).

Por outro lado, no domínio do ritual, destaca-se a prática dos sacrifícios, cujo conhecimento tem sido, todavia, entravado pela escassa documentação procedente da Lusitânia, sobretudo face ao material referente ao panteão (HOZ, 1986: 46). Como forma de colmatar esta insuficiência, este autor (HOZ, op. cit:: 47) preconiza a utilização do método comparativo, embora com a necessária cautela, mais concretamente a comparação com a tradição religiosa indoeuropeia, na qual os rituais sacrificiais terão constituído um sistema organizado. Neste sentido, a proposta de G. Dumézil (1958: 34-62) no âmbito dos estudos religiosos apresenta-se relevante, preconizando o estabelecimento de paralelos entre a religiosidade romana (posteriormente difundida nas províncias) e a indo-europeia, nomeadamente ao nível da classificação tripartida das divindades segundo as suas funções.

Todavia, no que respeita ao desenvolvimento da questão central do trabalho, não poderemos considerar alheias algumas noções de natureza terminológica e metodológica. No âmbito do estudo da epigrafia votiva peninsular, tem sido debatida a definição do conceito de divindade

\begin{tabular}{|l|l|l|l|l|l|l|}
\hline (C) Rev. Arqueologia Pública & Campinas, SP & v. 9 & n. 2 & $57-71$ & DEZ 2015 & ISSN 2237-8294
\end{tabular}




\section{Revista de Arqueologia Pública}

venerada pelas populações deste território em época anterior ao domínio romano, tendo sido concebidas e utilizadas várias designações, entre as quais divindade indígena, lusitana, hispânica, pré-romana, etc.; tratando-se de um problema não de nomenclatura, mas sim de significado histórico e sociocultural (ENCARNAÇÃO, 1971: 347). Neste trabalho, foi utilizada a definição de "indígenas" para estas divindades, tal como preconizado por este autor (ENCARNAÇÃO, 1971: 348-49 e 2002: 12), por evidenciar o seu carácter local e autóctone, distinguindo-as face às divindades de natureza global.

$\mathrm{Na}$ análise destas face às divindades romanas, não deverão ser esquecidas as dificuldades inerentes à determinação do caráter das divindades em geral, em parte devidas aos problemas levantados pela análise filológica dos teônimos. Pode ser inserida neste domínio a problemática dos critérios que tornam uma divindade romana ou não, entre os quais a sua anterioridade ou contemporaneidade em relação ao domínio romano e o nome ou epíteto da mesma, remetendo para esta questão as invocações a divindades romanas dotadas de epítetos locais (ENCARNAÇÃO, 1971: 349 e 1987a: 11).

J. Toutain (1907: 243 e 468) também abordara este problema, defendendo a insuficiência do teônimo latino como indicador seguro da romanidade, uma vez que estes poderão designar divindades autóctones veneradas na região em causa em época anterior à ocupação romana, cujo culto teria sido "encoberto" através da teonímia e formulário latinos, as quais teriam coexistido com os cultos nitidamente importados da religiosidade romana. No entender de alguns autores (BÚA, 2000: 21; ENCARNAÇÃO, 1987A: 8 e 2002: 12; LAMBRINO, 1965: 228), a identificação das divindades indígenas com outras romanas, designada interpretatio, poderá constituir um elemento informativo relevante para o melhor conhecimento da religiosidade da Lusitânia em época romana.

Por outro lado, no contexto dos problemas metodológicos, J. de Hoz (1986: 31) alertara para a insuficiência das fontes arqueológicas como base para o estudo das religiões, dada a transmissão destas através de uma série de atos que não deixam vestígios materiais, seguindo-o J. d'Encarnação (2002: 16). Também o foco da investigação da religiosidade da Lusitânia na vertente linguística e etimológica constitui um entrave, pela insuficiência na explicação das palavras na sua qualidade bidimensional, que engloba o significante (o lado "material" da palavra, isto é, a fonética) e o significado (HOZ, 1986: 33). Nesta perspectiva, a "funcionalidade" dos teônimos, ao remeterem para características definidoras das divindades, permitir-nos-ia controlar a etimologia proposta para a designação destas e avaliar a sua viabilidade semântica, se dispusermos de informações relativas à esfera de influência ou atividade das mesmas; a abordagem etimológica deverá então orientar-se para a confirmação e não para a definição das características das divindades, a qual deverá então basear-se no contexto material e social que nos é trazido pela epigrafia (HOZ, op. cit.: 34).

Já no domínio particular da documentação e sua interpretação, deveremos levar ainda em conta a escassez de notícias transmitidas pelos autores clássicos a respeito da religiosidade das

\begin{tabular}{|l|l|l|l|l|l|l|}
\hline (C) Rev. Arqueologia Pública & Campinas, SP & v. 9 & n. 2 & $57-71$ & DEZ 2015 & ISSN 2237-8294
\end{tabular}




\section{Revista de Arqueologia Pública}

comunidades indígenas da Hispânia (BLÁZQUEZ, 1990: 223); juntamente com a possibilidade de figurarem diferentes línguas no mesmo texto: a do dialeto em que surgiu o teônimo, do dialeto da zona de extensão do culto, cujos falantes terão gravado a inscrição, e do dialeto de origem do(s) antropônimo(s) nela incluído(s) (PRÓSPER, 2002: 37).

\section{O TESTEMUNHO DAS “PEDRAS GRAVADAS”: RECOLHA DOS DADOS}

No que respeita às fontes que propiciam o melhor conhecimento das divindades indígenas da Lusitânia, J. de Hoz (1986) salientara o potencial da epigrafia, reconhecendo porém as dificuldades de interpretação que poderão decorrer da adaptação da língua pré-romana à norma latina; partilhando J. d'Encarnação (1987a: 8 e 2002: 13) esta opinião, ao defender um melhor aproveitamento do monumento epigráfico enquanto fonte informativa. Efetivamente, no âmbito geográfico e cronológico deste trabalho, a inscrição votiva constituiu a principal fonte informativa sobre a religiosidade das populações, enquanto símbolo não apenas da veneração de determinadas divindades por parte dos indivíduos, mas também do estatuto social destes e do seu eventual envolvimento em atividades socioeconômicas.

No domínio da epigrafia, um dos mais relevantes métodos para a leitura e interpretação das inscrições consiste na elaboração de um levantamento epigráfico, no qual são reunidos todos os dados disponíveis sobre as epígrafes através de fichas descritivas. A importância destas justifica-se pelo fato de permitirem a integração do texto e do seu suporte numa série ou conjunto coerente de inscrições, estabelecido com base em determinados critérios (LASSÈRE, 2007²: 31); neste caso em particular, as epígrafes foram compiladas em função da sua natureza votiva, dentro do âmbito geográfico e cronológico definido, organizando-se ainda em subdivisões geográficas daquele a fim de facilitar a consulta do levantamento ${ }^{2}$.

Revela-se essencial à realização deste a consulta das grandes compilações epigráficas, como o segundo volume do CIL (HÜBNER, 1869) e as obras de H. Dessau (1974) e J. Vives (1971); para este âmbito geográfico em particular, revestiu-se de extrema importância a obra de J. d'Encarnação (1984). Já as inscrições descobertas em época posterior à publicação desta última foram levantadas com recurso às revistas epigráficas ainda em atividade, nomeadamente Ficheiro

\footnotetext{
${ }^{2}$ A saber: 1. Região de Ossonoba, 2., 3 e 4. Núcleos de Myrtilis, Mirobriga e Salacia, 5. Região de Pax Iulia (núcleo urbano e termo rural), 6. Região de Ebora (idem), 7. Região de Elvas, 8. Região de Ammaia (núcleo urbano e termo rural), 9, Região de Aritium Vetus, segundo a proposta de Encarnação, 1984 (as delimitações destes territórios são explicitadas infra no ponto 3.)
} 


\section{Revista de Arqueologia Pública}

Epigráfico ( $\mathrm{FE}$ ) e Hispania Epigraphica (HEp), não tendo sido esquecido também o potencial dos recursos eletrônicos, que têm desempenhado um papel cada vez mais relevante no registo das epígrafes, nomeadamente a base de dados da Hispania Epigraphica online (HEpOL).

O modelo de ficha descritiva utilizado neste trabalho apresenta-se consistente com os pressupostos de J. d'Encarnação (1987b: 11 e 13-14), P. Lassère (2007²: 31-33) e G. Susini (1997²: 17) a respeito dos critérios de registo e descrição das epígrafes, ao incluir os aspectos mais técnicos e objetivos daquele (quando aplicáveis), como o número de referência da inscrição, proveniência, contexto da sua descoberta, paradeiro atual, natureza do suporte, descrição do monumento, dimensões máximas e medidas interiores do campo epigráfico, características paleográficas do texto e bibliografia da inscrição; juntamente com os aspectos mais complexos e também mais passíveis de se deixarem influenciar pela subjetividade do epigrafista: transcrição da epígrafe de acordo com as normas correntes, variantes, tradução, comentário e datação ${ }^{3}$.

No contexto das técnicas de recolha dos dados, tem sido incluída a amostragem, concebida como uma seleção de apenas alguns dados considerados adequados como amostra representativa do conjunto na sua totalidade (CARMO, 1994: 291-99), a qual não se revela alheia ao domínio epigráfico. Para este trabalho em particular, após uma exclusão inicial das epígrafes exteriores ao âmbito cronológico e temático do mesmo, foram excetuadas aquelas desprovidas de teônimo/epíteto e elementos onomásticos inteligíveis, perfazendo um conjunto de 85 exemplares. Dentro deste, as inscrições dotadas de teônimo e/ou epíteto integraram posteriormente uma amostra orientada para a caracterização religiosa do espaço em análise, formada por 73 exemplares; enquanto a amostra constituída pelas epígrafes registrando dados onomásticos se direcionou para a caracterização sociojurídica, englobando também 73 exemplares.

Creio que cabe aqui explicitar alguns problemas inerentes às amostras epigráficas, nomeadamente o fato de estas poderem não corresponder totalmente à realidade representada no contexto espaço-temporal em questão, devido à possível existência de outras inscrições votivas por descobrir; à exclusão, aquando da seleção da(s) amostra(s), de diversos exemplares desprovidos de potencial informativo; à modesta dimensão do material epigráfico da maioria das regiões integrantes deste espaço geográfico (abarcando entre 1 e 6 exemplares), e consequentemente dos cultuantes registrados; e à presença de invocações a divindades desconhecidas nestas amostras. Outro dos problemas da utilização das epígrafes como fontes informativas prende-se à pluralidade de leituras e interpretações amiúde propostas para uma mesma inscrição por parte de distintos autores, sobretudo nos casos em que o estado de conservação se mostra menos favorável à inteligibilidade do texto.

\footnotetext{
${ }^{3}$ As inscrições serão doravante referidas pelo seu número de registo na obra de Encarnação, J. d' (1984): Inscrições romanas do conventus Pacensis (=IRCP), enquanto as epígrafes descobertas em época posterior à publicação desta obra serão indicadas com a referência da sua primeira publicação nas revistas epigráficas (nome e no/fascículo da revista, ano de publicação e ํㅡㄹ da epígrafe).
} 


\section{Revista de Arqueologia Pública}

No entanto, apesar destes constrangimentos, a documentação epigráfica continua a deter um apreciável potencial informativo. A observação de elementos como os suportes materiais, decoração, caracteres e paginação, formulário e onomástica dos indivíduos registrados afigura-se passível de nos permitir um melhor conhecimento das populações às quais atribuímos os exemplares epigráficos: suportes como as aras e árulas são frequentemente associados a populações de elevada romanidade, enquanto outros como estrelas remetem para o caráter mais autóctone da população (ENCARNAÇÃO, 1984: 813). Por seu lado, o cuidado na paginação e gravação, o formulário clássico e correto, e a graciosidade da decoração também apontam para um meio nitidamente romanizado, refletido em determinadas inscrições deste trabalho (IRCP 58, Loulé; IRCP 60, S. Bartolomeu de Messines; IRCP 146, Santiago do Cacém; IRCP 229, Beja; HEp 9, 1999, no 738, Alvito).

\section{TRATAMENTO DA INFORMAÇÃO RESULTANTE. A RELEVÂNCIA DE UMA PERSPECTIVA COMPARATIVA}

Como ficara já subentendido na divisão das amostras epigráficas, o desenvolvimento da questão central do trabalho apresenta-se marcado, do ponto de vista mais lato, por uma separação entre a caracterização religiosa, englobando os cultos e divindades, e social, focada nos respectivos cultuantes. Esta serviu o propósito de conferir maior clareza à estrutura geral do trabalho e o merecido destaque a cada óptica de análise, não devendo porém ser entendida de forma inflexível, dada a interligação existente entre ambas.

Dentro de cada uma destas esferas de análise, no seguimento de uma perspectiva comparativa, foi estabelecida uma distinção entre o mundo urbano e rural do âmbito geográfico mais lato (Sul do território atualmente português). Estes são, assim, cotejados no que diz respeito ao seu grau de romanização, tendo também vindo a ser traçada uma dicotomia entre ambos neste sentido, no contexto da qual tem sido atribuído ao espaço rural um maior conservadorismo sociocultural, que contrastaria com a nítida integração do âmbito urbano na norma romana (ALARCÃO, 2002 ${ }^{4}$ ).

Seguindo a perspectiva de J. d'Encarnação (1984: 741-47), podem ser integrados neste último os núcleos de Myrtilis (Mértola), Mirobriga (Santiago do Cacém) e Salacia (Alcácer do Sal), e ainda de Ammaia (S. Salvador de Aramenha, Marvão) ${ }^{4}$, Ebora (Évora), Pax lulia (Beja) e Ossonoba

\footnotetext{
${ }^{4}$ A região amaiense abrangeria, na sua globalidade, os atuais concelhos de Alter do Chão, Castelo de Vide, Crato, Marvão e Portalegre.
} 


\section{Revista de Arqueologia Pública}

(atual concelho de Faro $)^{5}$; enquanto os territórios rurais seriam constituídos pelos termos das últimas quatro regiões, juntamente com as regiões de Elvas e Aritium Vetus ${ }^{6} .0$ mundo rural caracteriza-se pela maior dimensão do material epigráfico, o que poderá ser relacionado com a mais vasta extensão destes territórios face aos núcleos urbanos.

Esta abordagem apresenta-se semelhante àquela seguida por J. C. Olivares Pedreño (2006) no contexto territorial da Hispânia céltica, na medida em que o autor, separando o mundo rural do urbano, se debruça sobre a representação dos cultos romanos e indígenas no referido contexto, com vista ao melhor conhecimento do processo de romanização religiosa do mesmo.

Embora não tenha sido tão nitidamente traçada uma separação, esteve também presente a noção da existência de uma zona mais setentrional e interior, que se estende até a área da antiga Ebora, abrangendo ainda a região de Elvas e as antigas regiões de Ammaia e Aritium Vetus; e outra mais meridional, que engloba regiões de natureza costeira, prosseguindo para Sul até o atual Algarve, e incluindo as regiões de Mértola, Santiago do Cacém, Alcácer do Sal e Beja.

Dentro dos âmbitos urbano e rural, são então cotejados os cultos indígenas e romanos, por um lado, e as distintas estruturas onomásticas e categorias sociojurídicas atribuídas aos dedicantes, por outro. No domínio das estruturas onomásticas, concebe-se neste trabalho uma distinção entre os exemplos de utilização do modelo quiritário (caracterizado pelo registo de tria nomina nos homens e duo nomina nas mulheres, com indicação da filiação), associado a indivíduos detentores de elevado grau de romanidade; e do nome único, comumente ligado a indivíduos de condição autóctone e do meio servil, consoante a origem do nome. A onomástica de origem grega tem sido a este meio, impondo-se contudo alguma cautela na atribuição de origem servil a indivíduos portadores destes nomes, dado que a posse dos mesmos poderá implicar, ao invés, que o seu pai ou avô possam ter sido escravos (LÓPEZ, 1993: 52-53); enquanto os antropônimos de filiação hispânica são considerados índices de uma condição autóctone.

Por seu lado, foram utilizadas as categorias que compõem o sistema sociojurídico da sociedade romanizada: cidadãos romanos, libertos e escravos (que constituem o meio servil no seu conjunto), e peregrini, ou indivíduos de condição autóctone. Todavia, cabe aqui referir alguns aspectos da evolução cronológica da norma onomástica romana, suscetíveis de constituir entraves à tarefa de determinação do estatuto sociojurídico dos indivíduos, nomeadamente a tendência para a omissão de certos elementos do modelo quiritário nas epígrafes, como a filiação e o prenome, a

\footnotetext{
${ }^{5}$ A região de Ossonoba corresponderia ao território do atual Algarve.

${ }^{6}$ Dada como correspondente à margem esquerda do Tejo, abrangendo os atuais concelhos de Abrantes, Almeirim, Chamusca, Gavião, Nisa e Ponte de Sor. Todas estas correspondências seguem os critérios empregues por Encarnação, 1984.
}

\begin{tabular}{|l|l|l|l|l|l|l|}
\hline (C) Rev. Arqueologia Pública & Campinas, SP & v. 9 & n. 2 & $57-71$ & DEZ 2015 & ISSN 2237-8294
\end{tabular}




\section{Revista de Arqueologia Pública}

partir de finais do séc. I d. C. e inícios do II, bem como a frequente omissão da referência ao estatuto de liberto ou escravo, através das expressões ser(vus/a) e lib(ertus/a) (LÓPEZ, 1993: 44 e 52).

As dificuldades inerentes a esta complexa tarefa justificaram então a concepção de três categorias destinadas a acomodar os casos mais problemáticos neste aspecto: condição incerta, não se afigurando maior ou menor a probabilidade de inserção do cultuante em determinada categoria; condição incerta, podendo todavia tratar-se de um cidadão romano; e condição incerta, podendo ser entendido como escravo.

\section{A ROMANIZAÇÃo RELIGIOSA DO ÂMBITO ESPAÇO-TEMPORAL EM QUESTÃO. ALGUMAS ILAÇÕES RETIRADAS DA INFORMAÇÃO OBTIDA}

- Atendendo à maior frequência de invocações de divindades romanas na globalidade do território em análise, encontramo-nos perante um cenário de predomínio dos cultos romanos no mesmo, o que aponta desde já para a sua apreciável romanidade. Este verifica-se não apenas no mundo urbano, mas também no seu correspondente rural, apesar do nítido aumento da representação dos cultos indígenas neste último.

- A distribuição dos teônimos e/ou epítetos indígenas nas epígrafes votivas aponta para uma melhor representação dos cultos e divindades autóctones na parte mais setentrional do mesmo, sobretudo nos seus territórios rurais. Porém, esta afirmação não aponta necessariamente para o menor grau de romanização desta zona, dado o predomínio dos cultos romanos na mesma, nomeadamente nas regiões de Ammaia e Elvas.

- Apresenta-se fragmentada a extensão e distribuição dos teônimos indígenas, dada a tendência de registo das divindades por uma única vez, como referira J. de Hoz (1986: 36), o que também se aplica a algumas divindades romanas. Por seu lado, a presença dos chamados epítetos tópicos permite-nos constatar o caráter local/étnico das divindades e a sua função tutelar (ENCARNAÇÃO, 1987a: 10; HOZ, 1986: 43).

- No domínio do ritual, documenta-se a prática sacrificial, aspecto no qual a religiosidade do espaço em análise se revela passível de comparação com a tradição religiosa indoeuropeia $(\mathrm{HOZ}$, 1986: 47), destacando-se a inscrição de Arronches (CARNEIRO et al., 2008). Nela se documenta a realização de sacrifícios a um conjunto de divindades indígenas organizadas numa hierarquia trifuncional, que Ihes atribui natureza soberana, guerreira e tópica (RIBEIRO, 2010: 42-56).

- Avulta o fenômeno de síntese observado entre o elemento romano e indígena. Este manifesta-se ao nível dos santuários e divindades, atendendo às inscrições que sugerem a

\begin{tabular}{|l|l|l|l|l|l|l|}
\hline (C) Rev. Arqueologia Pública & Campinas, SP & v. 9 & n. 2 & $57-71$ & DEZ 2015 & ISSN 2237-8294 \\
\hline
\end{tabular}




\section{Revista de Arqueologia Pública}

existência daqueles, refletindo uma eventual coexistência de santuários rurais de divindades indígenas com os de divindades autóctones "reformuladas" à maneira romana e com santuários romanos em contexto urbano e rural; e também dos cultuantes, pois o predomínio da onomástica latina e da cidadania romana em ambos coexiste com a persistência de alguma onomástica autóctone e indivíduos identificados como peregrini, sobretudo nos territórios rurais e setentrionais.

- Entre os indícios de elevado estatuto socioeconômico dos dedicantes que nos são trazidos pelas epígrafes, tanto do mundo urbano como rural, contam-se a ereção de estátuas, embora com reservas nalguns casos (IRCP 60, Faro; IRCP 230, Beja; FE 38, 1991, no 174, Borba) e ainda de um templo (HEp 17, 2008, oㅡ 212, Beja); o exercício de funções de prestígio (IRCP 146, Santiago do Cacém, registando um magister do culto de Vénus; IRCP 439, Alandroal, dedicada por um soldado da VII Legião Gémea Pia Félix) ${ }^{7}$; e a presença de gentilícios identificando populações detentoras de consideráveis potencialidades econômicas e sociais.

- Comprova-se então a precoce e sólida assimilação da norma sociocultural romana pelas comunidades do Sul do território atualmente português, parecendo confirmar-se este cenário face à parte mais setentrional do mesmo. Neste sentido, o mundo urbano e rural não poderão ser considerados de forma muito diferenciada entre si, manifestando-se os índices de romanidade apenas de forma ligeiramente mais notória no primeiro, o que parece contrariar a ideia de uma romanização claramente mais intensa dos territórios urbanos face aos seus homólogos rurais.

\section{SÍNTESE DOS CONTEÚDOS EXPOSTOS}

Em primeiro lugar, transparece claramente a inserção da temática deste trabalho - a religiosidade do Sul do território atualmente português em época romana - no âmbito de estudo das ciências sociais, o que influencia o conjunto de métodos utilizados na abordagem da mesma e determina as etapas inerentes ao seu processo de investigação, idênticas a qualquer temática explorada dentro deste âmbito de estudo.

\footnotetext{
${ }^{7}$ Excetuando as epígrafes entretanto perdidas, as inscrições aqui referidas encontram-se, na sua maioria, no Museu Nacional de Arqueologia (MNA), em Lisboa, cujo acervo engloba todas as formas de vestígios arqueológicos da totalidade do atual território português; algumas destas provêm da exposição temporária "Religiões da Lusitânia", enquanto a maioria permanece em depósito. Já as restantes encontram-se em museus de âmbito municipal (Museus de Ammaia, Loulé, Mação e Serpa) e regional (Museus de Beja, Elvas, Évora, Faro, Lagos e Marvão), cujas coleções não se restringem ao patrimônio arqueológico das regiões em causa, encerrando a generalidade dos elementos suscetíveis de divulgar e valorizar a sua história e cultura.
}

\begin{tabular}{|l|l|l|l|l|l|l|}
\hline (C) Rev. Arqueologia Pública & Campinas, SP & v. 9 & n. 2 & $57-71$ & DEZ 2015 & ISSN 2237-8294
\end{tabular}




\section{Revista de Arqueologia Pública}

Como tal, o desenvolvimento deste trabalho pressupôs a definição de uma questão central, enquadrada num contexto dogmático mais global e influenciável por certos problemas de índole terminológica e metodológica, o estabelecimento de objetivos e a existência de uma ou mais fontes informativas. Residindo a principal fonte na epigrafia votiva, pelo seu potencial informativo no domínio da vivência das sociedades antigas (entre as quais a romana), esta reveste-se de algumas particularidades, tal como a generalidade das fontes utilizadas na investigação científica, pressupondo a utilização de certas ferramentas metodológicas tornadas necessárias por esta natureza particular, com vista ao melhor aproveitamento possível do potencial informativo da epigrafia.

Nesta sucinta análise metodológica transparece ainda o peso da perspectiva comparativa neste trabalho, seguindo a linha de outros autores (por ex., OLIVARES, 2006) que dela haviam feito uso no seu desenvolvimento de temáticas similares, o que se afigura plausível considerando que as realidades sociais não podem ser percepcionadas de forma unilateral e homogênea, dada a intervenção de uma diversidade de elementos na composição das mesmas. Neste trabalho em particular, constatamos assim que a religiosidade das comunidades lusitano-romanas do Sul do território atualmente português se revela marcada por uma dinâmica interligação entre o elemento romano e o autóctone, que encontra expressão tanto na análise dos cultos e divindades, como dos cultuantes; a qual se manifesta não só numa escala regional mais lata, englobando toda a extensão mais meridional do País, face à sua parte mais setentrional, como também em ópticas de análise mais restritas, que se referem aos territórios urbanos e rurais.

\section{Referências bibliográficas}

ALARCÃO, J. de. O domínio romano em Portugal. Mem-Martins: Publicações Europa-América (Colecção Forum da História, 1), $2002^{4}$.

BLÁZQUEZ, J. M. La religión de los pueblos de la Hispania prerromana. Zephyrus, Salamanca, n. 43, p. 223-233, 1990.

BÚA, C. Estudio lingüístico de la teonimia lusitano-gallega. Salamanca. Dissertação de Doutoramento inédita, 2000.

CARMO, F. Religião e sociedade em análise: uma abordagem sociológica. Angra do Heroísmo: Livraria do Seminário Episcopal, 1994. 
CARNEIRO, A.; ENCARNAÇÃO, J. d'.; OLIVEIRA, J.; TEIXEIRA, C. Uma inscrição votiva em língua lusitana. Palaeohispanica, Zaragoza, n. 8, p. 167-178, 2008.

DESSAU, H. Inscriptiones Latinae Selectae. Dublin/Zurique: Weidmann (reedição do original de 1892), 1974.

DUMÉZIL, G. L'idéologie tripartie des Indo-Européens. Bruxelas : Latomus (Collection Latomus, vol. XXXI), 1958.

DURKHEIM, E. As formas elementares da vida religiosa (tradução de Paulo Neves). São Paulo: Martins Fontes Editora (Colecção Tópicos), 1996.

ENCARNAÇÃO, J. d'. O conceito de divindade indígena sob o domínio romano na Península Ibérica. Separata de AAVV (Org.). Actas do II Congresso Nacional de Arqueologia. Coimbra: Ministério da Educação Nacional e Junta Nacional da Educação, p. 347-351, 1971.

Inscrições Romanas do Conventus Pacensis: subsídios para o estudo da romanização. Coimbra: Instituto de Arqueologia da Faculdade de Letras, 2 vol., 1984. (Tese de Doutoramento em Arqueologia apresentada à Faculdade de Letras da Universidade de Coimbra).

26, p. 5-37, 1987a.

Divindades indígenas da Lusitânia. Separata de Conimbriga. Coimbra, n.

. Introdução ao estudo da epigrafia latina. Coimbra: Instituto de Arqueologia da Faculdade de Letras de Coimbra (Cadernos de Arqueologia e Arte, 1), 1987b²

Das religiões e das divindades indígenas na Lusitânia. In RIBEIRO, J. C. (Coord.). Religiões da Lusitânia - Loquuntur Saxa. Lisboa: Museu Nacional de Arqueologia, p. 1116, 2002.

ENCARNAÇÃO, J. d'; GUERRA, A. The current state of research on local deities in Portugal. In ARENAS-ESTEBAN, J. (Ed.). Celtic Religion across space and time. IX Workshop Fontes Epigraphici Religionum Celticarum Antiquarum (FERCAN). Molina de Aragón e Toledo: Centro de Estudios de Molina y Alto Tajo e Junta de Comunidades de Castilla-La-Mancha, p. 94-112, 2010. 


\section{Revista de Arqueologia Pública}

FE - Ficheiro Epigráfico. Coimbra: Instituto de Arqueologia da Faculdade de Letras de Coimbra, $1982-$

HEp - Hispania Epigraphica. Madrid: Universidad Complutense de Madrid, 1989-

HOZ, J. de. La religión de los pueblos prerromanos de Lusitania. In CHAPARRO, C. (Coord.). Manifestaciones religiosas en la Lusitania. Primeras Jornadas. Cáceres: Servicio de Publicaciones de la Universidad de Extremadura/Depto. de Ciencias de la Antigüedad, p. 31-49, 1986.

HÜBNER, E. Corpus Inscriptionum Latinarum (=CIL). Vol II. Berlim: Berolini, 1869.

LAMBRINO, S. Les cultes indigènes en Espagne sous Trajan et Hadrien. In PIGANIOL, A.; TERRASSE, H. (Org.). Les Empereurs Romains d'Espagne. Actes du Colloque International sur les empereurs romains d'Espagne. Paris: Centre Nationale de la Recherche Scientifique, p. 223-242, 1965.

LASSÈRE, J.-M. Manuel d'épigraphie romaine. Vol. I: L'individu - La cité. Paris: Picard (Antiquité/Synthèses, 8), 2007²

LÓPEZ, P. Epigrafía latina. Las inscripciones romanas desde los orígenes al siglo III d. C. Santiago de Compostela: Tórculo Ediciones, 1993.

MARX, K. A contribution to the critique of Hegel's Philosophy of Right introduction. DeutschFranzösische Jahrbücher. Paris, n. 7/10, 1844. Proofed and corrected by Andy Blunden (2005), and corrected by Matthew Carmody (2009). Disponível online em www.marxists.org/archive/marx/works/1843/critique-hpr/intro.htm, acedido em 29-07-2014.

OLIVARES, J. C. Cultos romanos e indigenismo: elementos para el análisis del proceso de romanización religiosa en la Hispania céltica. Lucentum, Alicante, n. 25, p. 139-157, 2006.

PRÓSPER, B. Lenguas y Religiones Prerromanas del Occidente de la Península lbérica. Salamanca: Ediciones Universidad (Acta Salmanticensia, 295), 2002. 


\section{Revista de Arqueologia Pública}

RIBEIRO, J. C. Algumas considerações sobre a inscrição em "lusitano" descoberta em Arronches. Palaeohispanica, Zaragoza, n. 10, p. 41-62, 2010.

ROSCOE, P. The Comparative Method. In SEGAL, R. (Ed.). The Blackwell Companion to the study of religion. Sussex: Wiley-Blackwell, 2009.

SUSINI, G. Epigrafia romana. Roma: Jouvence (Guide allo studio della civilità romana, X, 1), 1997³

TOUTAIN, J. Les Cultes Païens dans I'Empire Romain. Tome I. Les cultes officiels; les cultes romains et gréco-romains. Paris : Ed. Ernest Leroux (Bibliothèque de l'École des Hautes Études, Sciences Religieuses, 20), 1907. Disponível online em http://www.archive.org/details/lescultespaens01tout, descarregado em 05-12-2013.

VIVES, J. Inscripciones latinas de la España romana. Barcelona: Consejo Superior de Investigaciones Científicas de la Universidad de Barcelona, 1971.

WEBER, M. Économie e société. Vol. 1. Paris: Plon, 1995. 